\title{
How Can the Over-Use of Surveillance Colonoscopy After Polypectomy Be Modified?
}

\author{
Sung Pil Hong $\cdot$ Won Ho Kim
}

Published online: 29 July 2011

(C) Springer Science+Business Media, LLC 2011

It is evident that colorectal cancer screening programs have contributed to a decrease in mortality [1-3]. Since professional groups, especially gastroenterologists, generally prefer colonoscopy as the most effective tool for colorectal cancer prevention [2], a considerable proportion of people with adenomatous polyps are discovered at the time of screening. Accordingly, a large number of people require post-polypectomy surveillance, which places a huge burden on medical resources $[4,5]$. Recent data showing that $20 \%$ of colonoscopies performed in practice were for surveillance after polypectomy [6] indicate the importance of appropriate allocation of medical resources. Therefore, efficient and safe guidelines on surveillance colonoscopy are needed to decrease the cost, risk and over-use of colonoscopy.

Before the 1990s, because there was no available guidelines, annual follow-up colonoscopy was common practice after polypectomy. The National Polyp Study, showing that it was safe to defer the first follow-up colonoscopy for 3 years [7], raised the issue of the cost and burden of postpolypectomy surveillance, and eventually led to develop a guideline in 1997 that recommended a 3-year interval of colonoscopy after removal of adenomas [8, 9]. In 2003, the updated guideline recommended extended intervals of surveillance colonoscopy and introduced the concepts of risk stratification according to the results of index colonoscopy [10]. The observations of Atkin et al. [11] using sigmoidoscopy over 3- to 6-year intervals showed that persons with adenoma of less than 1-cm size and with no high-grade

S. P. Hong · W. H. Kim $(\square)$

Department of Internal Medicine, Institute of Gastroenterology,

Yonsei University College of Medicine, 250 Seongsanno,

Seodaemun-gu, Seoul 120-752, Korea

e-mail: kimwonho@yuhs.ac dysplasia were not at a higher risk for developing colorectal cancer. This data clearly showed that patients could be stratified into low-risk or high-risk groups according to the size of adenoma in index colonoscopy. Based on these observations, the guideline published in 2003 recommended the first follow-up colonoscopy after 5 years for low-risk patients [10]. In 2006, the updated guideline further emphasized risk stratification at index colonoscopy to encourage a shift from intense surveillance to surveillance based on risk [12]. Recent guidelines recommend the first follow-up colonoscopy after 3 years in people at high risk (three or more adenomas, high-grade dysplasia, villous features, or an adenoma $1 \mathrm{~cm}$ or larger in size). Follow-up colonoscopy after 5-10 years is recommended for people at lower risk who have one or two small $(<1 \mathrm{~cm})$ tubular adenomas with no high-grade dysplasia. Surveillance examination for hyperplastic polyps was first included in a 2006 guideline, and 10-year follow-up evaluation is recommended.

However, recent surveys have shown that a large proportion of clinicians do not follow the recommended guidelines. One national survey of surveillance colonoscopy after polypectomy in 1999 and 2000 showed that 54\% of gastroenterologists and $86.5 \%$ of general surgeons recommend surveillance examinations every 3 years or even more often for a small adenoma [13]. For a hyperplastic polyp, $24 \%$ of gastroenterologists and $54 \%$ of surgeons recommend surveillance. Another national survey in 2004 showed that $61 \%$ of primary care physicians (family medicine and internal medicine) recommend surveillance for a hyperplastic polyp after 5 years or less, and $71 \%$ recommend surveillance for a single tubular adenoma after 3 years or less [14]. A recent self-reported patient survey showed that $46.7 \%$ of subjects with one or two nonadvanced adenomas received a surveillance colonoscopy 
within 5 years [15]. These surveys consistently demonstrated the over-use of surveillance colonoscopy, especially in subjects with hyperplastic polyps or low-risk adenomas. The reasons why physicians are performing aggressive surveillance colonoscopy are unclear. Possible explanations include their disagreement or unfamiliarity with the guidelines, or other factors that are considered in making the decision, such as suboptimal bowel preparation, or concerns about the potential risk of missed cancers. One survey of gastroenterologists preparing for 2004 recertification showed that although $78 \%$ of respondents reported that they were familiar with the 2003 guideline, they correctly answered fewer than $60 \%$ of questions, and up to $76 \%$ disagreed with the recommendations and therefore performed surveillance colonoscopy sooner than recommended by the guidelines [16].

In this issue of the journal, Ransohoff and colleagues gave us further data regarding the over-use of surveillance colonoscopy, especially in persons with low-risk adenoma [17]. The present cross-sectional study was performed to evaluate the physicians' recommendations for postpolypectomy surveillance in a community practice in North Carolina. One hundred fifty-two gastroenterologists in 55 practices participated in the present study. Compared to previous surveys, the distinguishing point of this study was that the authors assessed the physicians' recommendations based on the medical records in their offices, not on the physicians' own reports. They reviewed the records of 10,089 average-risk persons who received a first-time screening colonoscopy in 2003. Among them, hyperplastic polyps were found in $4.5 \%$ of subjects, low-risk adenoma (less than $1 \mathrm{~cm}, 1$ or 2 adenomas) in $14.0 \%$, and high-risk adenoma (more than $1 \mathrm{~cm}, 3$ or more adenomas) in $7.5 \%$. The physicians recommended follow-up colonoscopy after 4-6 years in $24 \%$ of subjects with hyperplastic polyps, and after 1-3 years in $35 \%$ of those with only small adenomas. The surveillance interval recommended for high risk adenomas was longer than the 3 years that guidelines recommend for about $26 \%$.

Ransohoff and colleagues raise important issues about the quality of colonoscopy. This may be the main reason why physicians performed shorter intervals of follow-up colonoscopy than the recommended guidelines even though most of them are familiar with those guidelines. This practice is also related to the general fear of missing polyps or cancer, which could potentially precipitate legal action. This study revealed that the surveillance interval for colonoscopies tended to be shorter if bowel preparation was less than excellent, especially in those with low-risk adenoma. Although there are no guidelines for the interval of colonoscopy with suboptimal bowel preparation, most physicians prefer to recommend a shorter follow-up interval [18]. This is due to the fact that suboptimal bowel preparation increases the rate of missed adenomas, including advanced adenoma [19].

Another important problem is that the preparation quality was not reported in $32 \%$ of examinations. Thus, strengthening quality control of colonoscopy procedures through education will be the most forceful way to reduce the over-use of colonoscopy when the primary care physicians generally recommend shorter interval surveillance than recommended in the guidelines due to the lack of confidence in the quality of their colonoscopy.

In conclusion, Ransohoff and colleges demonstrated that surveillance colonoscopy is still over-used in community practice. However, from this study, we are able to show a possibility for improving our clinical practice based on evidence. This study suggests that education about the importance of risk stratification and qualified colonoscopy, such as bowel preparation and reporting, will reduce the burden of surveillance colonoscopy. Because the data was collected in 2003, it is difficult to simply apply the results of this study to recent practice. Therefore, we anticipate a follow-up study to evaluate changes in the decision-making processes of the same physicians after establishment of newer guidelines that further emphasize the importance of risk stratification and quality indicators of colonoscopy.

\section{References}

1. Levin B, Lieberman DA, McFarland B, et al. Screening and surveillance for the early detection of colorectal cancer and adenomatous polyps, 2008: a joint guideline from the American Cancer Society, the US Multi-Society Task Force on Colorectal Cancer, and the American College of Radiology. CA Cancer J Clin. 2008;58:130-160.

2. Rex DK, Johnson DA, Anderson JC, et al. American College of Gastroenterology guidelines for colorectal cancer screening 2009 [corrected]. Am J Gastroenterol. 2009;104:739-750.

3. Arditi C, Peytremann Bridevaux I, Burnand B, et al. Appropriateness of colonoscopy in Europe (EPAGE II). Screening for colorectal cancer. Endoscopy. 2009;41:200-208.

4. Vijan S, Inadomi J, Hayward RA, et al. Projections of demand and capacity for colonoscopy related to increasing rates of colorectal cancer screening in the United States. Aliment Pharmacol Ther. 2004;20:507-515.

5. Ladabaum U, Song K. Projected national impact of colorectal cancer screening on clinical and economic outcomes and health services demand. Gastroenterology. 2005;129:1151-1162.

6. Lieberman DA, De Garmo PL, Fleischer DE, et al. Patterns of endoscopy use in the United States. Gastroenterology. 2000;118: 619-624.

7. Winawer SJ, Zauber AG, O'Brien MJ, et al. Randomized comparison of surveillance intervals after colonoscopic removal of newly diagnosed adenomatous polyps. The National Polyp Study Workgroup. N Engl J Med. 1993;328:901-906.

8. Winawer SJ, Fletcher RH, Miller L, et al. Colorectal cancer screening: clinical guidelines and rationale. Gastroenterology. 1997;112:594-642. 
9. Byers $\mathrm{T}$, Levin B, Rothenberger D, et al. American Cancer Society guidelines for screening and surveillance for early detection of colorectal polyps and cancer: update 1997. American Cancer Society Detection and Treatment Advisory Group on Colorectal Cancer. CA Cancer J Clin. 1997;47:154-160.

10. Winawer S, Fletcher R, Rex D, et al. Colorectal cancer screening and surveillance: clinical guidelines and rationale-Update based on new evidence. Gastroenterology. 2003;124(2):544-560.

11. Atkin WS, Morson BC, Cuzick J. Long-term risk of colorectal cancer after excision of rectosigmoid adenomas. $N$ Engl J Med. 1992;326:658-662.

12. Winawer SJ, Zauber AG, Fletcher RH, et al. Guidelines for colonoscopy surveillance after polypectomy: a consensus update by the US Multi-Society Task Force on Colorectal Cancer and the American Cancer Society. Gastroenterology. 2006;130:1872-1885.

13. Mysliwiec PA, Brown ML, Klabunde CN, et al. Are physicians doing too much colonoscopy? A national survey of colorectal surveillance after polypectomy. Ann Intern Med. 2004;141: 264-271.

14. Boolchand V, Olds G, Singh J, et al. Colorectal screening after polypectomy: a national survey study of primary care physicians. Ann Intern Med. 2006;145:654-659.
15. Schoen RE, Pinsky PF, Weissfeld JL, et al. Utilization of surveillance colonoscopy in community practice. Gastroenterology. 2010;138(1):73-81.

16. Saini SD, Nayak RS, Kuhn L, et al. Why don't gastroenterologists follow colon polyp surveillance guidelines?: results of a national survey. J Clin Gastroenterol. 2009;43:554-558.

17. Ransohoff DF, Yankaskas B, Gizlice Z, Gangarosa L. Recommendations for post-polypectomy surveillance in community practice. Dig Dis Sci. (Epub ahead of print). doi:10.1007/s10620011-1791-y.

18. Ben-Horin S, Bar-Meir S, Avidan B. The impact of colon cleanliness assessment on endoscopists' recommendations for followup colonoscopy. Am J Gastroenterol. 2007;102:2680-2685.

19. Lebwohl B, Kastrinos F, Glick M, et al. The impact of suboptimal bowel preparation on adenoma miss rates and the factors associated with early repeat colonoscopy. Gastrointest Endosc. 2011;73:1207-1214. 